\title{
Phillips, Treacy, and Yoo Are 1991 MRS Fall Meeting Chairs
}

Twenty-six technical symposia are already in the works for the 1991 MRS Fall Meeting to be held December 2-7 in Boston, Massachusetts. The three chairs for this meeting, Julia Phillips, Michael Treacy and Man Yoo, bring a strong commitment to interdisciplinarity and scientific excellence.

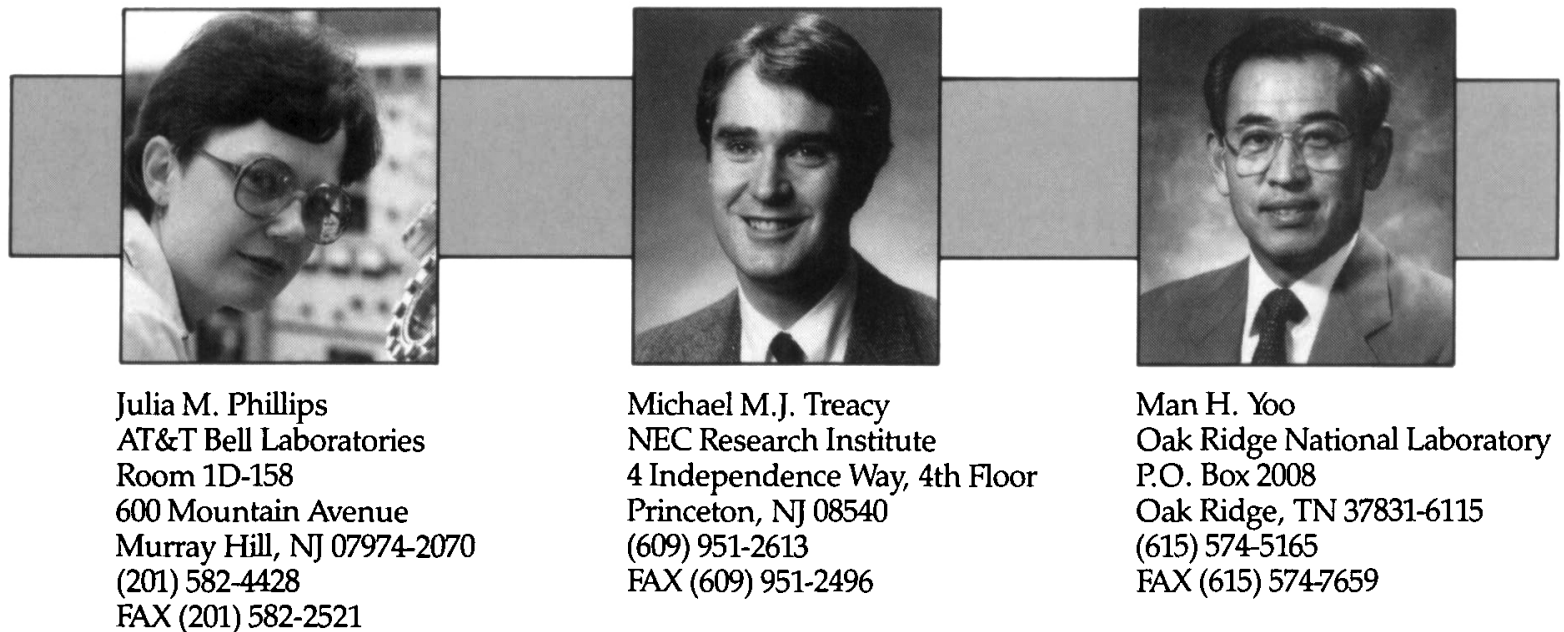

Julia M. Phillips is supervisor of the Thin Film Research Group at AT\&T Bell Laboratories, where her work involves the growth and characterization of high $\mathrm{T}_{\mathrm{c}}$ superconductor thin films with emphasis on relationships between the structure and electrical properties of these films. At Bell, she has also studied the growth and characterization of epitaxial insulators and metals on silicon and other semiconductors. This work included demonstrating the applicability of rapid thermal annealing to the improvement of heteroepitaxy, establishing a correlation between the detailed atomic arrangement and electrical properties and epitaxial insulator-semiconductor interfaces, and studying the phase sequence and electrical transport properties of ultrathin epitaxial metal films. She received a BS degree in physics from the College of William and Mary, and a PhD degreee in applied physics in 1981 from Yale University, where she studied the low energy electron impact excitation of rare gas atoms. A new negative ion resonance of helium was discovered during this work. Phillips is a member of MRS and the American Physical Society. She has served MRS as secretary, chair of several committees, and symposium organizer

"Technical meetings of the highest scientific caliber with a unique interdisciplinary approach are by far the most important activity of the Materials Research Society. It is both a privilege and a challenge to develop a meeting that preserves the special qualities that make it an identifiably MRS event while finding new ways to make it more valuable to the attendees."
Michael M.J. Treacy is senior research scientist at the NEC Research Institute, Inc., where he is involved with basic materials research into computer and communications technologies, using transmission electron microscopy (TEM) and computer modeling. He received a BA degree in physics in 1976 from St. John's College, Cambridge University. While studying for his $\mathrm{PhD}$ under the direction of Archie Howie at the Cavendish Laboratories (Cambridge University), Treacy explored new TEM techniques for studying supported catalysts. There he found that the " $Z$ contrast" technique, which uses a high-angle annular detector in a scanning transmission electron microscope (STEM), was strikingly successful at detecting extremely fine dispersions of platinum particles on model catalyst supports. After graduation, Treacy accepted a one-year position with King-Ning Tu at IBM Yorktown Heights, New York, where he studied thin film growth. Afterward, he carried out 18 months of study with the Centre National Etudes de Télecommunications in Bagneux, France, where he did STEM studies of spinodal decompostion in InGaAsP quaternary semiconductor alloys. Treacy, an MRS member since 1980, served as an MRS symposium organizer in 1987.

"I have always been impressed by the broad scope of materials issues addressed by MRS. The Society successfully draws together researchers working in fields as diverse as micro-electronics, catalysis, polymers and infrastructure materials. This interdisciplinarity is a great strength of MRS which we intend to reinforce in the 1991 Fall meeting."
Man H. Yoo is currently a senior research staff member in the Metals and Ceramics Division of Oak Ridge National Laboratory. His research interests span dislocation theory, plastic deformation, radiation damage, high-temperature flow and fracture, and mechanical properties of intermetallic compounds and other structural materials. He received a PhD in physical metallurgy from Michigan State University in 1965, and was a guest scientist at the Institute of Solid State Research, KFA Jülich, Germany, and at the Institute for Materials Research, Tohoku University, Japan. Yoo, a member of MRS, AIME, and ASM International, co-chaired the MRS symposium on Interfacial Structure, Properties, and Design at the 1988 MRS Spring Meeting. As co-chair of the 1991 MRS Fall Meeting, Yoo's goal is to bring about interdisciplinary approaches to the problems of outstanding unresolved issues in materials research and development efforts.

"I believe that MRS meetings should provide an interdisciplinary forum to cover structural materials as well as functional materials, not only for experienced specialists, but also for thinkers who can break the traditional mold."

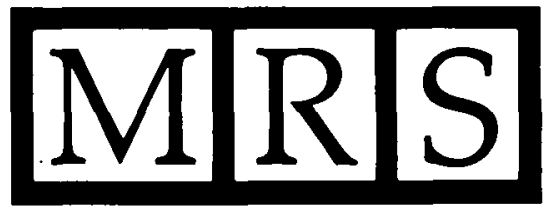

